\title{
Bicaval versus standard technique in orthotopic heart transplantation: A systematic review and meta-analysis
}

\author{
Maike Schnoor, ${ }^{a}, *$ Torsten Schäfer, PhD, ${ }^{a, *}$ Dagmar Lühmann, MD, ${ }^{a}$ and Hans H. Sievers, PhD
}

Supplemental material is available online.
From the Institute of Social Medicine, ${ }^{\mathrm{a}}$ Medical University of Schleswig-Holstein, Campus Luebeck, Luebeck, Germany; and the Department of Cardiovascular Surgery, ${ }^{\mathrm{b}}$ Medical University of Schleswig-Holstein, Campus Luebeck, Luebeck, Germany.

Address for reprints: Maike Schnoor, Institute of Social Medicine, Medical University of Schleswig-Holstein, Campus Lübeck, Beckergrube 43-47, 23552 Lübeck, Germany (E-mail: Maike.schnoor@uk-sh.de).

*Maike Schnoor and Torsten Schäfer contributed equally.

J Thorac Cardiovasc Surg 2007;134:1322-31 $0022-5223 / \$ 32.00$

Copyright (๑) 2007 by The American Association for Thoracic Surgery

doi:10.1016/j.jtcvs.2007.05.037
Objective: We aimed to evaluate and compare the efficacy of the bicaval and the biatrial standard techniques in orthotopic heart transplantation.

Methods: A systematic review with meta-analysis was performed. As data sources, we used the electronic databases EMBASE and Medline (1966-August 2006), hand searching in 4 journals, expert consultation, and reference lists of reviews. Observational and randomized and prospective and retrospective controlled trials that reported outcomes on the 2 techniques of heart transplantation were considered.

Results: A total of 23 retrospective and 18 prospective studies were included. Metaanalyses of prospective trials including between 228 and 472 patients revealed significant superiority of the bicaval technique in comparison with the biatrial procedure for early atrial pressure (weighted mean difference, $-3.95 ; 95 \%$ confidence interval, -6.50 to -1.40 ), perioperative mortality (odds ratio, $0.41 ; 95 \%$ confidence interval, 0.17 to 0.98 ), tricuspid valve regurgitation (odds ratio, $0.23 ; 95 \%$ confidence interval, 0.15 to 0.36), and sinus rhythm (odds ratio, $7.01 ; 95 \%$ confidence interval, 2.57 to 19.13 ). The latter also showed a significant difference in the analysis of retrospective studies (odds ratio, 2.69; $95 \%$ confidence interval, 1.55 to 4.66 ).

Conclusion: In summary, this systematic review and meta-analysis provides evidence of clinically relevant beneficial effects of the bicaval technique in comparison with those of the standard technique. Nevertheless, the longer-term beneficial effects of the bicaval technique remain to be evaluated.

$\mathrm{S}$ ince the first reported case in $1967,{ }^{1}$ heart transplantation has become the treatment of choice for patients with end-stage heart failure. Today, more than 3000 heart transplantations are performed yearly worldwide. ${ }^{2}$ During several decades, the biatrial or standard technique for orthotopic cardiac transplantation, based on the description of Cass and Brock ${ }^{3}$ and Lower and Shumway, ${ }^{4}$ has been used successfully. This technique requires, to some extent, the excision of the posterior part of the donor left atrium and incision of the right atrium from the inferior vena cava toward the right atrial appendage to avoid injury of the sinus node. The atrial anastomoses can be performed straightforward, reducing from 8 possible single-vessel anastomoses for complete transplantation to 4 . However, there are theoretic disadvantages with this standard technique, including enlarged, figure-of-eight configured right and left atria probably interfering with their contractile and electrophysiologic, as well as tricuspid and mitral valve, functions. ${ }^{5}$ Two alternative techniques of orthotropic heart transplantation were developed and introduced into clinical practice around 1990 to overcome these potential imperfections. In 1989, Banner and colleagues, ${ }^{6}$ from the Harefield Group, introduced the total transplantation technique that preserves the integrity of both the donor atria by anastomosing pulmonary veins as a cuff on each side of the heart and also the vena cava separately. Sievers and co-workers, ${ }^{7}$ in 1991 , and the Wythenshawe group, ${ }^{8}$ in 1993, introduced into clinical practice the bicaval transplantation technique, which is characterized by 2 arterial, 1 left atrial, and 2 caval anasto- 


\section{Abbreviation and Acronym}

$\mathrm{CI}=$ confidence interval

moses, preserving the right atrium intact and leaving only a small posterior part of recipient left atrial tissue between both pulmonary veins.

There are several studies comparing these 3 different techniques of orthotopic heart transplantation that have also been summarized in recent reviews. ${ }^{9-11}$ It is essential to summarize and appraise the available studies under the rigorous methods of evidence-based medicine to help in the decision making on what technique should be preferred. This has not been done thus far.

We therefore aimed to compare the more recent bicaval heart transplantation techniques (Figure 1), ${ }^{6,7}$ both combined under the term "bicaval techniques," with the standard procedure (Figure 1) for clinically relevant outcomes and, by implementing the methods of a systemic review and meta-analysis, to achieve the best available level of evidence for that subject.

\section{Materials and Methods}

\section{Data Collection}

To obtain the most comprehensive evidence base, we implemented 4 independent literature search strategies: a search in electronic databases, hand searching, consultation of an experienced cardiovascular surgeon (HHS), and reference lists of recent reviews.

We conducted a literature search in PubMed and the database of the German Institute of Medical Documentation and Information, including EMBASE and Medline, from 1966 through August 2006 using the following search strategy: [("heart transplantation") OR ("cardiac transplantation") AND bicaval]. In addition, the Cochrane library of systematic reviews was visited.

For a hand search, the 4 journals (The Annals of Thoracic Surgery, The European Journal of Cardiothoracic Surgery, The Journal of Heart and Lung Transplantation, and The Journal of Thoracic and Cardiovascular Surgery) that provided the most

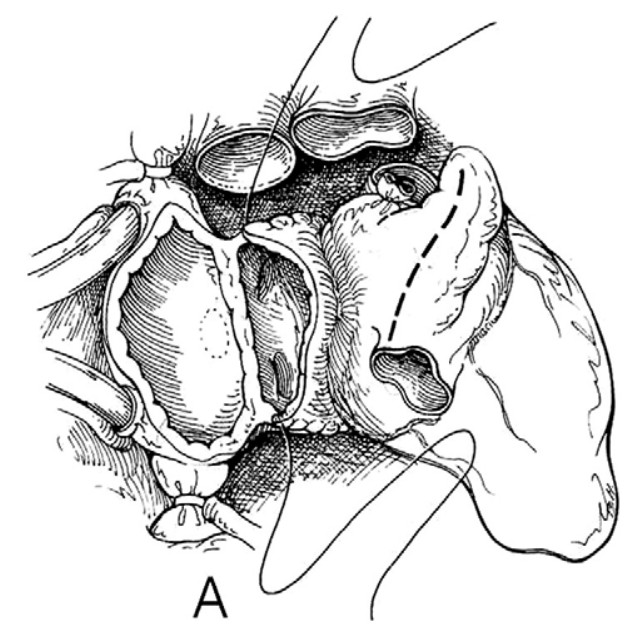

Figure 1. Schematic drawings of the standard biatrial heart transplantation technique $(A)^{6}$ and the 2 bicaval techniques $\left(B^{6}\right.$ and $\left.C^{7}\right)$, both preserving the right atrium intact.
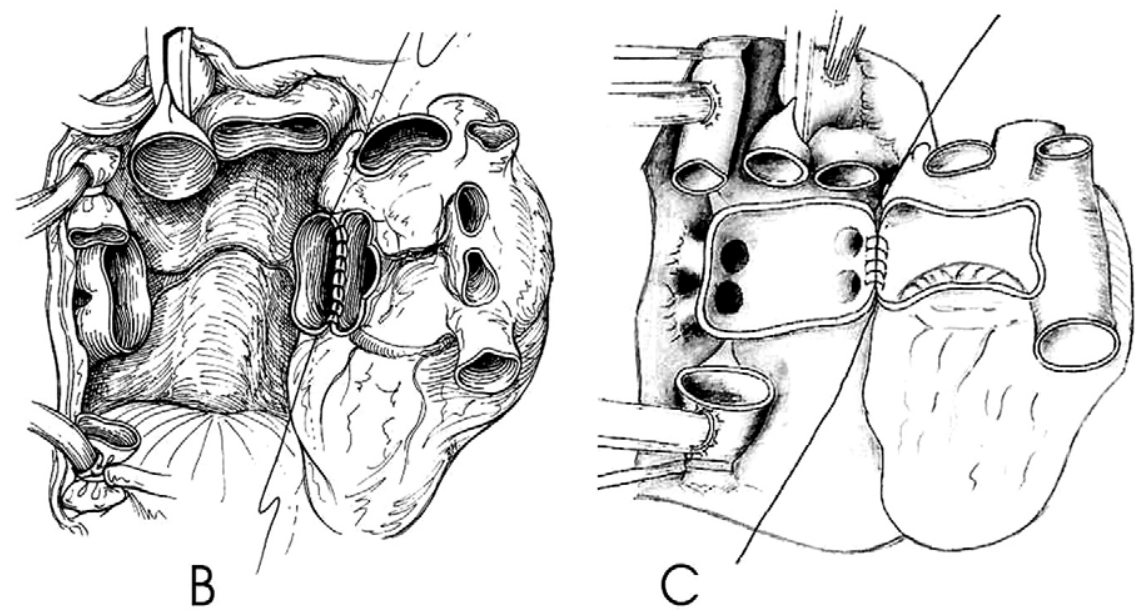
studies on the use of the bicaval technique thus far were identified. A hand search was then performed for the period from 1999 through June 2005.

In addition, HHS was asked to give hints on further literature and research groups that were not covered by the achieved studies. Furthermore, the reference lists of recent reviews were checked for relevant literature. Studies had to evaluate orthotopic heart transplantation by using the bicaval technique to be eligible for inclusion. ${ }^{6,7}$ We included only studies in the English or German languages. The search was not limited to randomized controlled trials. Observational controlled and uncontrolled, prospective and retrospective studies were included. The search was not age restricted. We excluded letters, comments, case reports and series, and nonhuman studies.

A 2-stage filter process applying the eligibility criteria was implemented by screening titles and abstracts first and then full texts. Both stages of the filter process were performed independently by 2 investigators (DL, TS). Results were then compared and showed identical results.

\section{Data Extraction and Critical Appraisal}

The data extraction and critical methodologic appraisal of the included studies was undertaken by MS. Levels of evidence were assigned to each study according to the Oxford Centre of Evidencebased Medicine. For the detailed methodologic assessment, a standardized form, which was developed on the basis of the Scottish Intercollegiate Guideline Network checklist, and an evaluation sheet of the German Institute for Quality and Efficiency in Health Care were used. Both are standardized instruments for the quality assessment of randomized controlled trails. The extracted information included lead author, publication year, intervention and observation period, study group characteristics (number, sex, and age), indication, criteria of inclusion and exclusion, techniques of the operation, statistical methods, outcomes, and adverse events. Quantitative results, either as means and standard deviations or rates, were summarized in tables.

With respect to the methodologic quality of the study, we further appraised the randomization process (sequence generation and allocation concealment), blinding, statistical methods, baseline characteristics of both groups, and handling of losses to follow-up.

\section{Outcome Measures}

All reported outcomes were retrieved and could be divided into 3 groups. The first group included clinically relevant outcomes, which were assessed in more than 2 studies in a comparable way and on which a meta-analysis could be performed. This group included intraoperative ischemic time of transplantation, permanent pacemaker insertion, early mortality (30-day mortality), 1-year survival, 3-year survival, duration of hospital stay, and atrial pressure in the early postoperative period. Furthermore, tricuspid valve regurgitation and sinus rhythm after cardiopulmonary bypass, although measured at different time points in prospective studies (Table E1), were considered.

A second group included outcome parameters that were determined in few studies only or at different time points: pulmonary vascular resistance, hemodynamic parameters (eg, pulmonary artery pressure, systolic blood pressure, right atrial pressure, cardiac index, and cardiac output), tricuspid valve regurgitation examined in retrospective studies, mitral valve regurgitation, need for a temporary pacemaker, and duration of intensive care unit stay.

The last group included outcomes that were determined only in single studies, such as the hemodynamic vasomotor responses to lower body negative pressure. These results were not considered in our review.

\section{Statistical Analyses}

We reported and summarized descriptive results as either means or rates according to the original publications. Meta-analyses were performed for outcomes as mentioned above for prospective and retrospective controlled trials separately. The software RevMan 4.2 (Cochrane Collaboration, http://www.cc-ins.net/RevMan/) was used for these analyses. Odds ratios or weighted differences of the means and corresponding 95\% confidence intervals (CIs) were reported as measures of association and stability. Heterogeneity among studies for every outcome was assessed by using the Cochrane Q test. Fixed-effect models were chosen in case no significant heterogeneity among studies was observed. Otherwise, random-effect models are presented. Sensitivity analyses were performed by comparing random and fixed-effect models, evaluating the effect of omitting influential studies, presenting funnel blots for parameters in which fixed-effect models were used with more than 3 included studies, and omitting studies with overlapping patient samples.

\section{Results}

\section{Literature Search}

PubMed revealed 90 and EMBASE and Medline revealed 95 potentially relevant studies. Duplicates were excluded, and a total of 95 references remained. In addition, 9 studies were provided by HHS, and 5 studies were identified by hand searching. Overall, 109 publications were retrieved. In the 2 screening processes 38 and 30 studies were excluded for reasons that are given in detail in Figure 2. Finally, we included 41 studies in our review. ${ }^{\text {E1-E41 }}$

\section{Description of the Studies}

The descriptive characteristics of the included 23 retrospective and 18 prospective studies, as well as the levels of evidence, are given in Tables 1 and 2, respectively. Four retrospective and 2 prospective trials were studies without a control group. The transplantation techniques could be divided into the standard technique described by Cass and Brock ${ }^{3}$ and Lower and Shumway ${ }^{4}$ and the bicaval technique introduced by Sievers and colleagues ${ }^{7}(n=30)$ or Banner and associates ${ }^{6}$ $(\mathrm{n}=9)$. In 2 studies the bicaval technique was not explained in detail. ${ }^{\mathrm{E} 1, \mathrm{E} 2}$ Overall, the retrospective studies included 753 patients undergoing heart transplantation by means of the standard technique, 203 patients undergoing heart transplantation according to the method of Banner and associates, ${ }^{6}$ and 517 patients undergoing heart transplantation according to the method of Sievers and colleagues. ${ }^{7}$ The prospective studies included 318 patients with the standard technique and 305 


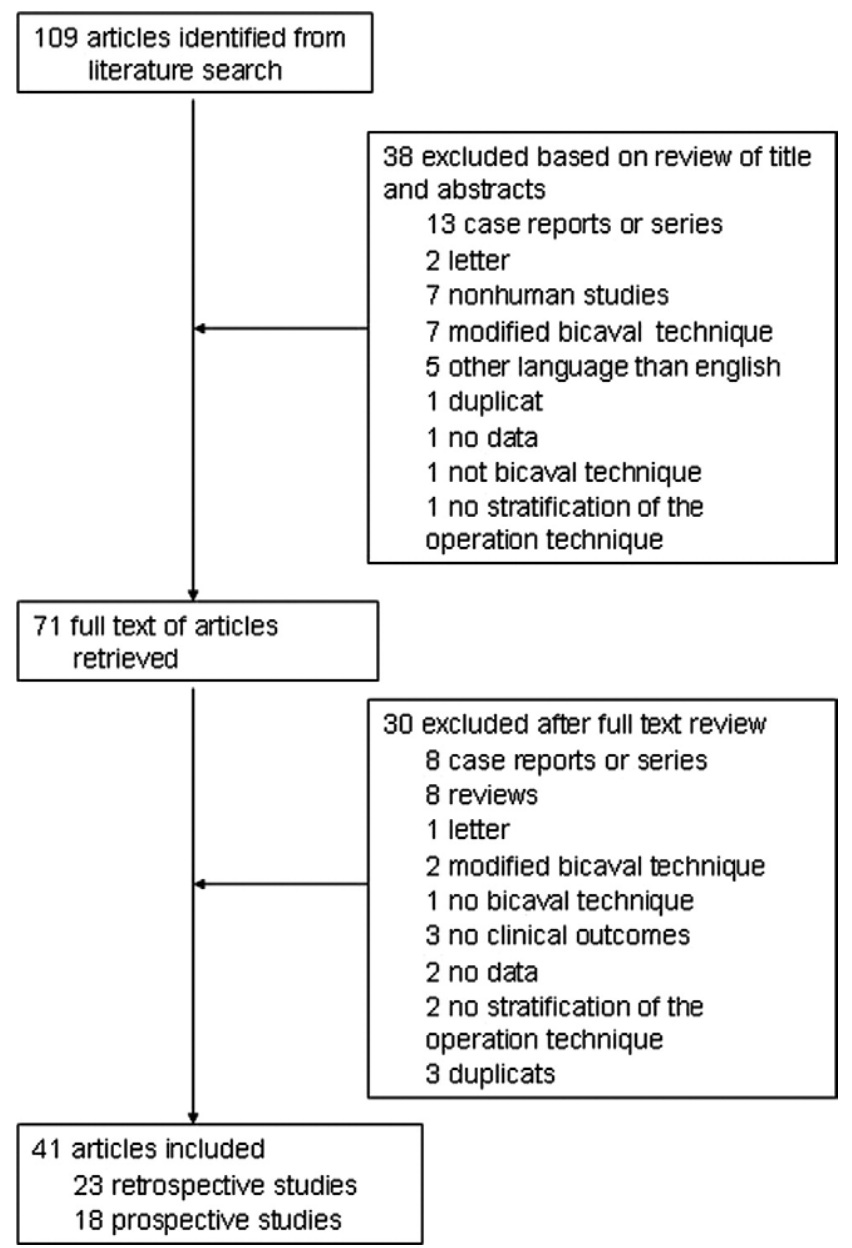

Figure 2. Flow chart of study selection.

patients with the bicaval technique. ${ }^{7}$ One study included 10 patients receiving the bicaval technique but did not specify the transplantation technique. Several studies were carried out in the same setting and investigated in part the same study population but different outcomes. Five of the retrospective studies $^{\mathrm{E} 3-\mathrm{E} 7}$ were conducted in the Cedars-Sinai Medical Centre, Los Angeles, California. One of the prospective ${ }^{\mathrm{E} 8}$ and one of the retrospective ${ }^{\mathrm{E} 9}$ studies were conducted at the University of Pavia, Italy. We included 4 prospective studies of the Whythenshawe Hospital in Manchester, United Kingdom. ${ }^{\text {E10-E13 }}$ Two prospective studies ${ }^{\mathrm{E} 14, \mathrm{E} 15}$ were performed at the Temple University Hospital in Philadelphia, Pennsylvania, but at different times, and 3 studies were performed at the University of Kiel, Germany. ${ }^{12, E 16-E 18}$ Because of overlapping study periods, only the study with the longest study period was considered.

The mean age of the population of the included studies ranged between 14.8 and 58.0 years, and the proportion of men was about $80 \%$. The most frequent indications for receiving orthotopic heart transplantation were ischemic or dilated cardiomyopathy and valvular heart diseases.

\section{Methodologic Quality}

Prospective studies. Most of the studies had potential or obvious methodologic limitations. Two of the included 18 prospective studies were uncontrolled trails. In 9 studies the study population was randomized to the operation technique, in most of them $(n=8)$ on an alternate basis. The latter cannot be considered as adequate because the allocation was foreseeable. One study did not describe the randomization technique at all. The study population consisted of less than 20 patients per group in 8 studies. Two studies failed to give information about inclusion or exclusion criteria. The time between transplantation and observation was shorter in the bicaval group compared with the standard group in 4 studies. For 2 studies the observation time point is unknown. Another 2 studies did not give information on the indication for transplantation. In all but 2 controlled studies, ${ }^{\text {E14,E19 }}$ the study groups (bicaval and standard) were comparable regarding age, sex and preoperative parameters. One study ${ }^{\mathrm{E} 14}$ showed a significant age difference between study groups, and the other study ${ }^{\mathrm{E} 19}$ reported a significant difference in the preoperative right atrial pressure.

Retrospective studies. We included 23 retrospective studies in our review. Four of the studies were not controlled by a patient group undergoing heart transplantation by means of the standard technique. In 9 studies the allocation to a study group occurred by pseudorandomization (time intervals). Some centers compared the time periods before and after the introduction of the bicaval technique. In 3 studies the observation period was shorter for the bicaval group than for the standard group. Four studies reported no exact observation period. In 4 studies the sample size was small ( $<20$ patients per group). Inclusion and exclusion criteria were given in 15 studies, and the indication for heart transplantation was given in another 15 studies.

\section{Outcomes}

Meta-analyses. The results of the meta-analyses are displayed in Figure 3 for prospective and Figure E1 for retrospective studies.

The intraoperative ischemic time was longer in patients undergoing bicaval techniques. For prospective studies, a nonsignificant weighted mean difference of 3.7 minutes was obtained (Figure 3, A). The 7 included retrospective studies showed heterogeneity and resulted in a nonsignificant difference of 15.8 minutes (Figure E1, A).

The summary of 3 prospective studies each proved a significantly reduced early atrial pressure of $4.0 \mathrm{~mm} \mathrm{Hg}$ (Figure 3,B) and a significantly reduced perioperative mortality of 59\% (relative risk reduction; Figure $3, C$ ) by means of the bicaval technique. The proportion of patients with 
TABLE 1. Basic characteristics of included retrospective studies

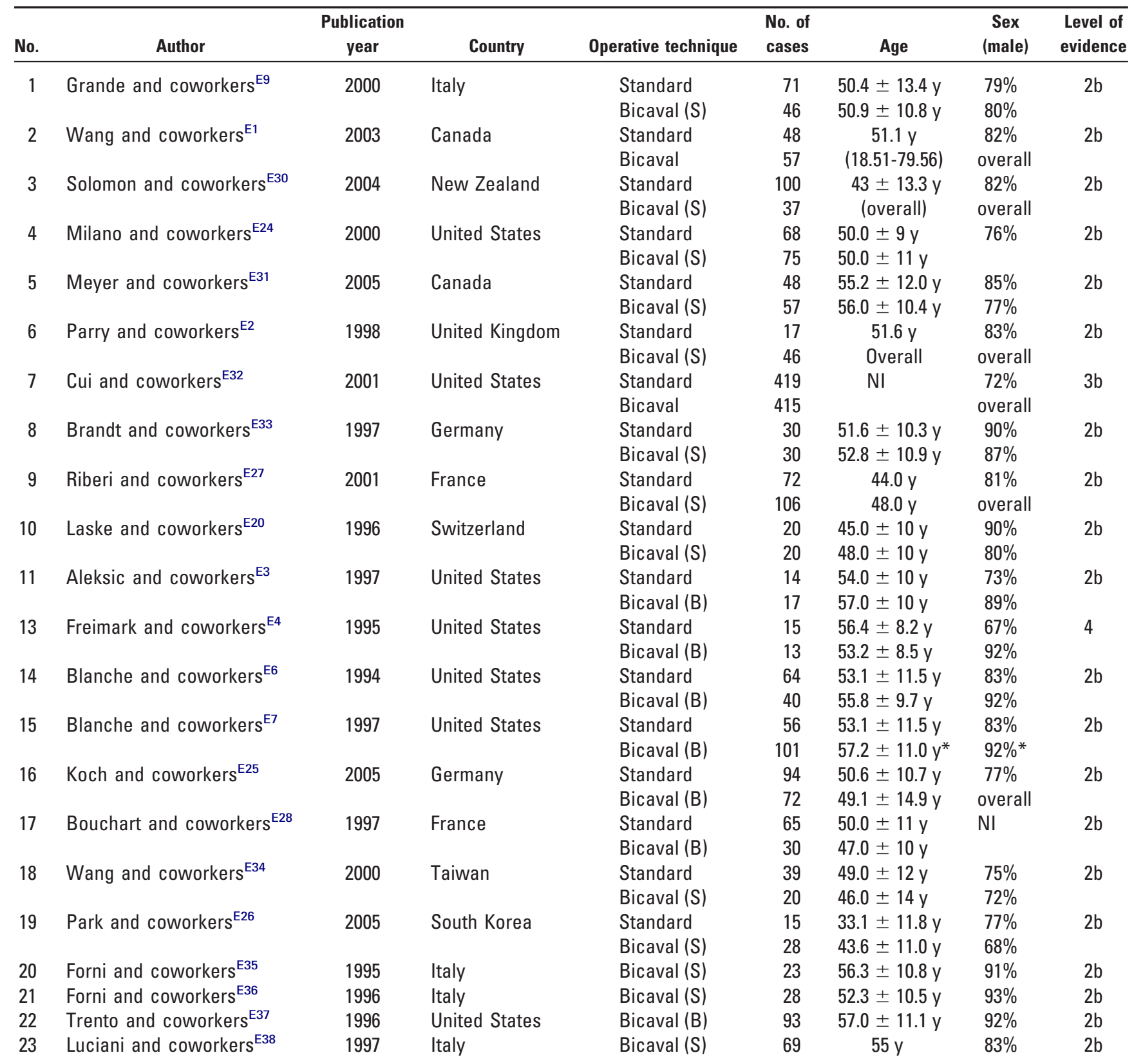

Study groups: Grande and Traversi; Aleksic, Blanche, Trento, and Freimark; Forni and Luciani. See the online-only reference list for further information. $B$, Banner and colleagues ${ }^{6} ; S$, Sievers and associates ${ }^{7} ; N I$, no information. ${ }^{*} P<.05$.

tricuspid valve regurgitation was reduced significantly by $77 \%$ in the bicaval group according to the summarized results of 7 prospective studies (Figure 3,D). In case the assessment of tricuspid valve regurgitation was graded, only moderate and severe cases were considered, and in case multiple observation points were given, results of the latest observation were included. According to 2 prospective studies, a sinus rhythm was achieved significantly more frequently with the bicaval technique (Figure $3, D$ ). It turned out that the meta-analyses of prospective studies only included those that implemented the bicaval transplantation technique according to Sievers and associates, ${ }^{7}$ with the exemption of the study of Beniaminowitz and coworkers, ${ }^{\text {E19 }}$ in which both bicaval techniques were used. ${ }^{6,7}$

The summary of 4 retrospective studies showed a nonsignificant reduction in hospital stay of 1 day in the bicaval group (Figure E1, B). Patients undergoing the bicaval technique also had a nonsignificant $88 \%$ risk reduction for a 
TABLE 2. Basis characteristics of the included prospective studies

\begin{tabular}{|c|c|c|c|c|c|c|c|c|}
\hline No. & Author & Publication & Country & Operative technique & $\begin{array}{l}\text { No. of } \\
\text { cases }\end{array}$ & Age & $\begin{array}{c}\text { Sex } \\
\text { (male) }\end{array}$ & $\begin{array}{l}\text { Level of } \\
\text { evidence }\end{array}$ \\
\hline \multirow[t]{2}{*}{1} & Pahl and coworkers ${ }^{\mathrm{E} 39}$ & 2003 & United States & Standard & 14 & $14.8 \pm 3.4 y$ & $\mathrm{NI}$ & 4 \\
\hline & & & & Bicaval (S) & 5 & $17.7 \pm 3.2 y$ & & \\
\hline \multirow[t]{2}{*}{2} & Sievers and coworkers ${ }^{\mathrm{E} 16}$ & 1994 & Germany & Standard & 10 & $49.7 \pm 13.1$ y & $70 \%$ & $2 b$ \\
\hline & & & & Bicaval (S) & 8 & $56.3 \pm 9.3 y$ & $75 \%$ & \\
\hline \multirow[t]{2}{*}{3} & Leyh and coworkers ${ }^{\mathrm{E} 17}$ & 1995 & Germany & Standard & 12 & $50.3 \pm 10.4$ y & $83 \%$ & $2 b$ \\
\hline & & & & Bicaval (S) & 15 & $52.2 \pm 10.3 y$ & $93 \%$ & \\
\hline \multirow[t]{2}{*}{4} & Aziz and coworkers ${ }^{\mathrm{E} 21}$ & 1999 & United Kingdom & Standard & 161 & $\mathrm{NI}$ & $\mathrm{NI}$ & $2 b$ \\
\hline & & & & Bicaval (S) & 88 & & & \\
\hline \multirow[t]{2}{*}{5} & Aziz and coworkers ${ }^{\mathrm{E} 22}$ & $1999 a$ & United Kingdom & Standard & 105 & $49.0 \pm 9.9 y$ & $84 \%$ & $2 b$ \\
\hline & & & & Bicaval (S) & 96 & $47.0 \pm 11.2 \mathrm{y}$ & $88 \%$ & \\
\hline \multirow[t]{2}{*}{6} & Sarsam and coworkers ${ }^{\mathrm{E} 40}$ & 1993 & United Kingdom & Standard & 20 & $\mathrm{NI}$ & $\mathrm{NI}$ & $2 b$ \\
\hline & & & & Bicaval (S) & 20 & & & \\
\hline \multirow[t]{2}{*}{7} & Traversi and coworkers ${ }^{\mathrm{E} 8}$ & 1996 & Italy & Standard & 27 & $45.0 \pm 10 y$ & $93 \%$ & $2 b$ \\
\hline & & & & Bicaval (S) & 22 & $50.0 \pm 12 y$ & $73 \%$ & \\
\hline \multirow[t]{2}{*}{8} & McDowell and coworkers ${ }^{\mathrm{E} 41}$ & 2000 & United Kingdom & Standard & 7 & 44.7 y & $100 \%$ & $2 b$ \\
\hline & & & & Bicaval (S) & 10 & $45.0 \mathrm{y}$ & $100 \%$ & \\
\hline \multirow[t]{2}{*}{9} & Beniaminowitz and coworkers ${ }^{\mathrm{E} 19}$ & 1997 & United States & Standard & 10 & $\mathrm{NI}$ & $\mathrm{NI}$ & 4 \\
\hline & & & & Bicaval (S and B) & 10 & & & \\
\hline \multirow[t]{2}{*}{10} & Grant and coworkers ${ }^{\mathrm{E} 10}$ & 1995 & United Kingdom & Standard & 35 & 49.2 y & $89 \%$ & $2 b$ \\
\hline & & & & Bicaval (S) & 31 & $44.1 \mathrm{y}$ & $81 \%$ & \\
\hline \multirow[t]{2}{*}{11} & El Gamel and coworkers ${ }^{\mathrm{E} 12}$ & 1996 & United Kingdom & Standard & 13 & $52.0 \pm 8.5 y$ & $77 \%$ & $2 b$ \\
\hline & & & & Bicaval (S) & 24 & $49.0 \pm 9.0 y$ & $71 \%$ & \\
\hline \multirow[t]{2}{*}{12} & El Gamel and coworkers ${ }^{\mathrm{E} 11}$ & 1995 & United Kingdom & Standard & 35 & $50 \mathrm{y}$ & $80 \%$ & $2 b$ \\
\hline & & & & Bicaval (S) & 40 & 53 y & $78 \%$ & \\
\hline \multirow[t]{2}{*}{13} & El Gamel and coworkers ${ }^{\mathrm{E} 13}$ & 1997 & United Kingdom & Standard & 20 & $49.0 \pm 6.1 \mathrm{y}$ & $65 \%$ & $2 b$ \\
\hline & & & & Bicaval (S) & 20 & $52.0 \pm 4.2 y$ & $75 \%$ & \\
\hline \multirow[t]{2}{*}{14} & Rothman and coworkers ${ }^{\mathrm{E} 14}$ & 1996 & United States & Standard & 33 & $56.0 \pm 8.0 y$ & $73 \%$ & $2 b$ \\
\hline & & & & Bicaval (S) & 37 & $49.0 \pm 13.0 \mathrm{y}^{*}$ & $76 \%$ & \\
\hline \multirow[t]{2}{*}{15} & Weisbrod and coworkers ${ }^{\mathrm{E} 29}$ & 2004 & Australia & Standard & 6 & $58.0 \pm 3.0 y$ & $67 \%$ & $2 b$ \\
\hline & & & & Bicaval (S) & 9 & $49.0 \pm 4.0 y$ & $67 \%$ & \\
\hline \multirow[t]{2}{*}{16} & Deleuze and coworkers ${ }^{\mathrm{E} 23}$ & 1995 & France & Standard & 40 & $49.8 \pm 8.0 y$ & $80 \%$ & $2 b$ \\
\hline & & & & Bicaval (S) & 41 & $45.6 \pm 11.0 y$ & $80 \%$ & \\
\hline 17 & Jahnke and coworkers ${ }^{\mathrm{E} 18}$ & 1995 & Germany & Bicaval (S) & 9 & $43.0 \pm 5.9 y$ & $\mathrm{NI}$ & $2 b$ \\
\hline 18 & Jeevanandam and coworkers ${ }^{\mathrm{E} 15}$ & 2004 & United States & Bicaval (S) & 60 & 52 y & $63 \%$ & $2 b$ \\
\hline
\end{tabular}

Study groups: Sievers, Leyh, and Jahnke; Aziz, Sarsam, Grant, and El Gamel; Rothman and Jeevandam. See the online-only reference list for further information. $B$, Banner and colleagues ${ }^{6}$; $S$, Sievers and associates ${ }^{7} ; N I$, no information. ${ }^{*} P<.05$.

permanent pacemaker implantation (Figure E1, C). Furthermore, 1-year and 3-year mortality was reduced in patients who underwent the bicaval technique by $40 \%$ and $36 \%$, respectively (nonsignificant; Figure E1, $D$ and $E$ ). The summary of retrospective studies also indicated a significantly higher proportion of patients achieving sinus rhythm with the bicaval technique (Figure E1, F).

Outcomes not included in the meta-analyses. The quantitative results of the outcome measurements not included in the meta-analysis are shown in Table E1. In summary, superiority of the bicaval technique introduced by Sievers and associates ${ }^{7}$ is indicated for the outcomes "need for temporary pacemaker,"E9-E11,E20 "right atrial pressure 12 months after transplantation,, $\mathrm{E} 3, \mathrm{E} 7, \mathrm{E} 21$ "pulmonary artery pressure after 1 year," erative day,"E22-E24 "mitral valve regurgitation,"E7,E11 “tricuspid valve regurgitation,"E7,E20,E24-E26 and "left atrial thrombosis." "E27,E28 No differences were seen for "pulmonary vascular resistance,"E3,E9 "systolic blood pressure,"E5,E29 "cardiac output,"

Sensitivity analysis. A comparison of the results of fixed- and random-effect models is displayed in Table E2. Overall, the effect estimates did not differ substantially by either model. As expected, the higher variability under the random-effect assumption led to loss of statistical significance in some cases (perioperative mortality in prospective studies and permanent pacemaker in retrospective studies).

We excluded influential studies in some models and compared the results as given in Table E3. The superi- 
Review: Prospective Studies

Comparison: 01 Bicaval vs. Standard $\begin{array}{ll}\text { Comparison: } & 01 \text { Bicaval vs. Stan } \\ \text { Outcome: } & 01 \text { lschemic time }\end{array}$

Study

\begin{tabular}{l} 
or sub-category N \\
\hline
\end{tabular}

Deleuze

Rothrnan
Aziz 1

\begin{tabular}{l}
$\mathrm{N}$ \\
\hline 41 \\
37
\end{tabular}

Bicaval

Mean (SD)

(SD)

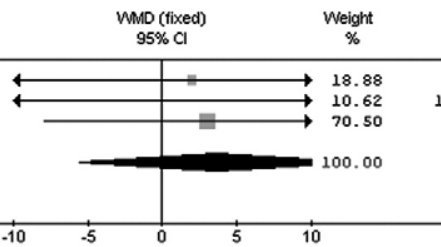

MMO (fixed

Total $(95 \% \mathrm{Cl}) \quad 174$

$\begin{array}{ll}41 & 138.00(51.00) \\ 37 & 225.00(64.00) \\ 96 & 182.00(40.00)\end{array}$

Test for overall effect: $Z=0.78(P=0.43)$

A

Favours bicaval Favours standard

$\begin{array}{ll}\text { Review: } & \text { Prospective Studies } \\ \text { Comparison: } & 01 \text { Bicaval vs. Standard }\end{array}$

Outcome: $\quad 03$ Right atrial pressure, early

Study

or sub-category

Deleuze

(a)

Aziz 1

\begin{tabular}{cr} 
N & \multicolumn{1}{c}{$\begin{array}{c}\text { Bicaval } \\
\text { Mean (SD) }\end{array}$} \\
\hline 20 & $4.90(2.10)$ \\
41 & $12.60(7.00)$ \\
55 & $7.90(3.10)$ \\
&
\end{tabular}

Total $(95 \% \mathrm{Cl})$

116

Test for heterogeneity $\mathrm{Chi}^{2}=16.78, \mathrm{df}=2(P=0.0002), \mathrm{I}^{2}=88.1 \%$

Test for overall effect: $Z=3.04(P=0.002)$

B

Review. Prospective studies

Comperison 01 Bicaval va. Standord

auconte: 02 perioper otive mortality

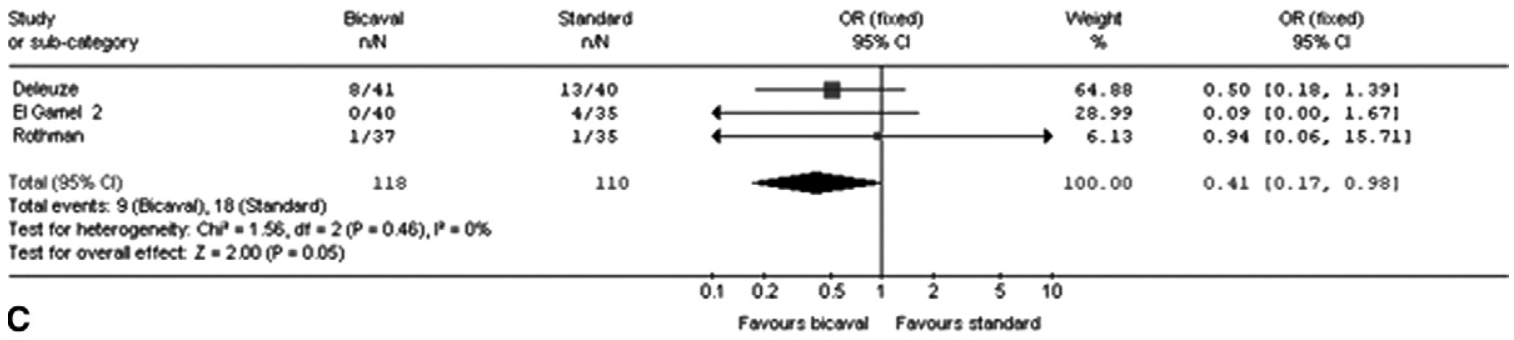

Review: Prospective Studies

Comparison: 01 Bicaval vs. Standard

Outcome: $\quad 06$ Sinus rhythm

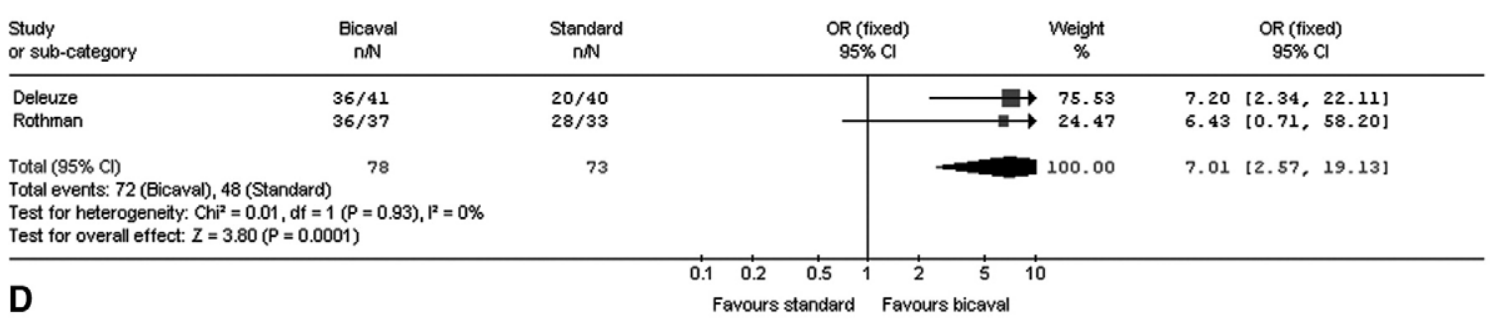

Review: Prospective Studies

Comparison: 01 Bicaval vs. Standard

Outcome: $\quad 05$ Tricuspid valve regurgitation

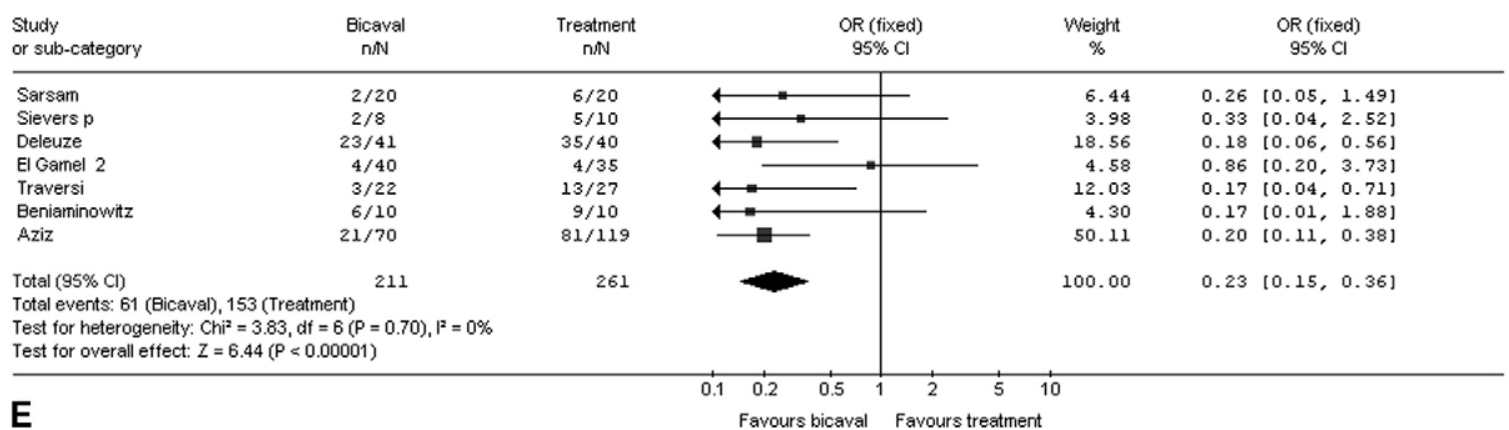

E

Favours bicaval Favours treatment

Figure 3. Meta-analyses of prospective studies. A, Ischemic time. B, Early atrial pressure. C, Perioperative mortality. D, Sinus rhythm. E, Tricuspid valve regurgitation. $O R, 0$ dds ratio. 


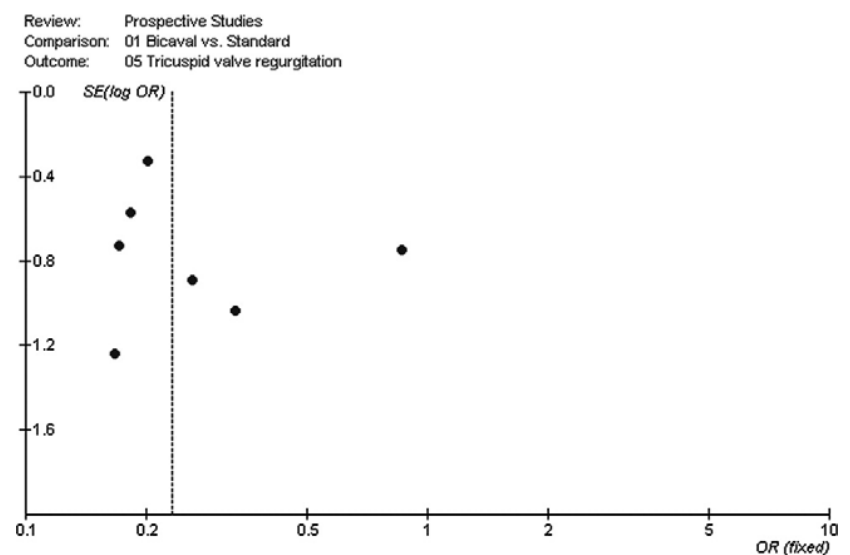

Figure 4. Funnel blot for prospective studies on tricuspid valve regurgitation. $O R, 0$ dds ratio.

ority of the bicaval technique was enhanced for the outcomes "early atrial pressure" in prospective studies and "1-year survival" in retrospective studies. For the outcomes "permanent pacemaker" and "3-year survival," as obtained in retrospective studies, the results gained statistical significance. Hospital stay seems to be longer with the bicaval technique rather than reduced when omitting an influential study.

The funnel blot of prospective studies on tricuspid valve regurgitation does not indicate a substantial effect of publication bias (Figure 4).

To exclude overlapping, the analyses on "early right atrial pressure" and "tricuspid valve regurgitation" in prospective studies were repeated by omitting the studies of Sarsam, ${ }^{\mathrm{E} 40}$ El Gamel, ${ }^{\mathrm{E} 12}$ and Aziz, ${ }^{\mathrm{E} 21}$ respectively. The early right atrial pressure was still reduced by $3.32 \mathrm{~mm} \mathrm{Hg}$ in the bicaval group, but statistical significance was no longer reached $(-8.80 ; 2.17)$. Tricuspid valve regurgitation was significantly reduced to the same degree in the bicaval group (odds ratio, 0.20 ; 95\% CI, 0.12-0.32). In retrospective studies the analyses on "ischemic time," "permanent pacemaker," and "3-year survival" were repeated by omitting the studies of Freimark, ${ }^{\mathrm{E} 5}$ and Aleksic, ${ }^{\mathrm{E} 3}$ respectively. The ischemic time was longer (13.7 minutes) and the need for permanent pacemakers (odds ratio, 0.14; 95\% CI, 0.011.1) and 3-year survival were reduced (odds ratio, 0.81; 95\% CI, 0.29-2.25) in the bicaval group. As before, none of these results reached statistical significance.

\section{Discussion}

This systematic review and meta-analysis demonstrated the significant superiority of the bicaval technique of orthotopic heart transplantation compared with the standard technique for some clinically relevant parameters, particularly right atrial pressure, perioperative mortality, tricuspid regurgita- tion, and sinus rhythm, according to prospective studies. For pediatric orthotopic heart transplantation, comparably excellent results have been reported with the standard biatrial technique. ${ }^{13}$ In addition, the biatrial technique might be preferred in certain cases of caval size mismatches, reoperation, or complex anatomy.

Heart transplantation in its most anatomic form would require 8 circumferential anastomoses of 4 pulmonary veins, 2 venae cavae, and 2 arteries. This technique, however, has several shortcomings, such as prolonged ischemic time, potentially difficult accessible suture lines in case of bleeding, anastomotic stenoses, and surgical complexity. Therefore, different transplantation techniques were developed experimentally to reduce the number of anastomoses. Berman and coworkers in $1957^{14}$ sutured the donor left atrium to cuffs around the pulmonary veins of the recipient on each side, reducing the number of anastomoses to 6 . Berman and associates ${ }^{14}$ left the posterior cuff of the recipient left atrium in place, reducing the number of anastomoses to 5. Cass and Brock, ${ }^{3}$ in 1959, and Lower and Shumway, ${ }^{4}$ in 1960, introduced the concept of 2 atrial and 2 arterial anastomoses, reducing the number of anastomoses to 4 .

This latter technique has been the standard clinical procedure since 1967, when the first human heart transplantation was performed by Barnard. ${ }^{1}$ Major parts of the recipient right and left atria are left in situ, the donor left atrium is partially excised, and the donor right atrium is incised from the inferior vena cava to the right atrial appendage. Postoperatively, the atria are acutely enlarged, showing a figure-of-eight configuration. ${ }^{5}$

Theoretically, these morphologic alterations might interfere with hemodynamic, electrophysiologic, innervative, and valvular function of the donor heart. Therefore former experimental alternative surgical principles were introduced into clinical practice recently. In 1989, Banner and associates ${ }^{6}$ first used the total transplantation technique, leaving the left and right atria completely intact. In 1991, Sievers and colleagues ${ }^{7}$ introduced clinically the bicaval technique, preserving the right atrium intact, only using 2 vena caval anastomoses, and leaving a small bridge of recipient left atrial tissue in place for simple left atrial anastomosis similar to those of the standard technique. During the last 15 years, the bicaval technique has become the most commonly used procedure for orthotopic heart transplantation. ${ }^{15}$ Different refinements of the principal technique have been used, such as interrupted sutures for the caval anastomosis with absorbable or unabsorbable material, and performed during the ischemic state or even leaving some right atrial bridge between the superior and inferior vena cava. ${ }^{16,17}$

This meta-analysis provides evidence that the expected theoretic advantages of bicaval transplantation in 
comparison with the standard technique have come true in clinical practice. In prospective trials, a reduction in right atrial pressure was found. The absolute difference in right atrial pressure is probably of no clinical relevance at rest. Conclusions with respect to clinical relevance under exercise with increased tricuspid regurgitation cannot be drawn. ${ }^{\text {E17 }}$

The higher rate of sinus rhythm after transplantation, the significant reduced rate of tricuspid valve regurgitation, the prevention of contraction abnormalities by the acute atrial enlargement with the standard technique, and the asynchrony of recipient and donor atrial innervation probably have contributed to the beneficial hemodynamic effects after bicaval transplantation. ${ }^{18-20}$ The enlargement and distension of the atria after the standard technique might not only induce impairment of electrical impulse initiation and conduction, as well as trigger arrhythmias, ${ }^{21,22}$ but also promote atrial thrombus formation most likely avoided by the bicaval technique. ${ }^{23, \mathrm{E} 27}$ There was a trend toward reduced permanent pacemaker

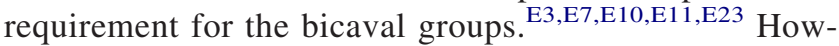
ever, also with the standard technique, the incidence of permanent pacemaker implantation can be kept comparably low when sinus node area is protected. ${ }^{\mathrm{E} 30, \mathrm{E} 33, \mathrm{E} 34}$

Furthermore, Bernardi ${ }^{24}$ found that the bicaval technique leads to an increased parasympathetic reinnervation compared with the standard technique, which might be of clinical relevance because an increase in control of blood pressure by larger reflex changes in heart rate might improve adaptation to various stimuli and to physical exercise.

Potential shortcomings of the bicaval technique include the marginally prolonged ischemic transplantation time of some minutes, which is likely of no clinical relevance, as well as some kind of stenosis at the level of the venous anastomoses. Both problems, however, can be neutralized by refined surgical techniques, such as performing anastomoses with the unclamped aorta and partially interrupted caval sutures. Furthermore, it can be discussed whether the longer hospital stay (when omitting an influential study) in the bicaval group is related to the particular surgical technique or the patient's clinical conditions.

This review has limitations. Although we implemented several strategies to obtain all relevant studies, including searches in electronic databases, hand searching, contact with experts, and screening of actual reference lists, it cannot be excluded that we have missed some information.

The quality of the review is reflected by the quality of the included single studies. Well-performed single studies can provide valid information and bear the potential advantage of a low variability in important parameters, such as myocardial protection, reperfusion techniques, or immunosup- pression. The majority of studies were retrospective in nature. These rather observational retrospective cohort studies have not implemented a rigorous randomization principle, which makes these studies prone to several biases, including selection and information bias (Level of evidence 2b). Furthermore, in 2 studies it is not always ascertained that the outcomes were obtained in a standardized and comparable way, which downgraded these studies to level of evidence 4 (poor-quality cohort studies). We identified 7 prospective randomized trials. All studies did not describe the randomization technique in detail or the randomization was on alternate basis, which downgraded these studies to level of evidence 2b (low-quality randomized controlled trial). Overall, the study quality was limited mainly because of a small sample size, lack of randomization, and blinding. Blinding should be possible for the patient, and an independent outcome assessment should be introduced.

Some reports were based on overlapping patient samples. We therefore performed meta-analyses with results from different centers only. The results changed only marginally. The estimate on early right atrial pressure in prospective studies lost its statistical significance.

Another potential limitation of meta-analysis is that different studies assessed outcomes in different ways and at different time points. We included in the meta-analysis studies assessing tricuspid valve regurgitation at different time points. This could bias our results and should be considered in the interpretation. The different time points could influence the pacemaker implantation, as well as the tricuspid valve insufficiency. Especially the latter might be impaired by biopsy and rejection. In addition, differences in the protocols of the practical performances of the outcome assessments cannot be ruled out, which might have affected comparability. There might also be a time trend in survival because of changing conditions in heart transplantation, which is not related to a particular transplantation technique.

A consequence for future studies should be the use of a minimum set of clinically relevant outcomes, which must be measured in a standardized and comparable way.

In summary, this systematic review and meta-analysis proves evidence of clinically relevant beneficial effects of the bicaval technique in comparison with the standard technique of orthotopic heart transplantation, which warrants careful consideration for further decision making. As a result of this analysis, the perioperative mortality seems to be reduced significantly in subjects after bicaval transplantation. Nevertheless, the longer-term beneficial effects of the bicaval technique remain to be evaluated, especially with regard to exercise capacity ${ }^{\mathrm{E} 16}$ and patient-oriented outcomes, such as health-related quality of life (Short Form-36).

We are grateful for the excellent support in medical data management and hand searching by Mrs D.S. Saravi. 


\section{References}

1. Barnard $\mathrm{CN}$. The operation. A human cardiac transplant: an interim report of a successful operation performed at Groote Schuur Hospital, Cape Town. S Afr Med J. 1967;41:1271-4.

2. Taylor DO, Edwards LB, Boucek MM, Trulock EP, Waltz DA, Keck $\mathrm{BM}$, et al. Registry of the International Society for Heart and Lung Transplantation: twenty-third official adult heart transplantation report-2006. J Heart Lung Transplant. 2006;25:869-79.

3. Cass MH, Brock R. Heart excision and replacement. Guys Hosp Rep. 1959;108:285-90.

4. Lower RR, Shumway NE. Studies on orthotopic homotransplantation of the canine heart. Surg Forum. 1960;11:18-9.

5. Angermann CE, Spes CH, Tammen A, Stempfle HU, Schutz A, Kemkes BM, et al. Anatomic characteristics and valvular function of the transplanted heart: transthoracic versus transesophageal echocardiographic findings. J Heart Transplant. 1990;9:331-8.

6. Banner NR, Khaghani A, Fitzgerald M, Mitchell AG, Radley-Smith R, Yacoub MH. The expanding role of cardiac transplantation. In: Unger F, editor. Assisted circulation. Berlin: Springer-Verlag; 1989.

7. Sievers HH, Weyand M, Kraatz EG, Bernhard A. An alternative technique for orthotopic cardiac transplantation, with preservation of the normal anatomy of the right atrium. Thorac Cardiovasc Surg. 1991;39:70-2.

8. Sarsam MA, Campbell CS, Yonan NA, Deiraniya AK, Rahman AN. An alternative surgical technique in orthotopic cardiac transplantation. J Card Surg. 1993;8:344-9.

9. Morgan JA, Edwards NM. Orthotopic cardiac transplantation: comparison of outcome using biatrial, bicaval, and total techniques. J Card Surg. 2005;20:102-6.

10. Miniati DN, Robbins RC. Techniques in orthotopic cardiac transplantation: a review. Cardiol Rev. 2001;9:131-6.

11. Liao KK, Bolman RM. Operative techniques in orthotopic heart transplantation. Semin Thorac Cardiovasc Surg. 2004;16:370-7.

12. Jahnke AW, Ley R, Bernhard A, Sievers HH. Atrial natriuretic peptide release at rest and with exercise after cardiac transplantation with bicaval anastomoses. J Thorac Cardiovasc Surg. 1995;110:1600-5.
13. Coskun O, Parsa A, Coskun T, El Arousy M, Blanz U, von Knyphausen E, et al. Outcome of heart transplantation in pediatric recipients. Experience in 128 patients. ASAIO J. 2007;53:107-10.

14. Berman EF, Goldberg M, Akman LC. Experimental transplantation of the heart. In: 22nd Annual Congress, US and Canadian Section, International College of Surgeons; Chicago, Ill; 1957.

15. Aziz TM, Burgess MI, El Gamel A, Campbell CS, Rahman AN, Deiraniya AK, et al. Orthotopic cardiac transplantation technique: a survey of current practice. Ann Thorac Surg. 1999;68:1242-6.

16. Kitamura S, Nakatani T, Bando K, Sasako Y, Kobayashi J, Yagihara T. Modification of bicaval anastomosis technique for orthotopic heart transplantation. Ann Thorac Surg. 2004;72:1405-6.

17. Tsilimingas NB. Modification of bicaval anastomosis: an alternative technique for orthotopic cardiac transplantation. Ann Thorac Surg. 2003;75:1333-4.

18. Valantine HA, Appleton CP, Hatle LK, Hunt SA, Stinson EB, Popp RL. Influence of recipient atrial contraction on left ventricular filling dynamics of the transplanted heart assessed by Doppler echocardiography. Am J Cardiol. 1987;59:1159-63.

19. Downie HG. Homotransplantation of the dog heart. Arch Surg. 1953; 66:624-36.

20. Williams JF Jr, Sonnenblick EH, Braunwald E. Determinants of atrial contractile force in the intact heart. Am J Physiol. 1965;209: 1061-8.

21. Boyden PA, Hoffman BF. The effects on atrial electrophysiology and structure of surgically induced right atrial enlargement in dogs. Circ Res. 1981;49:1319-31.

22. Little RE, Kay GN, Epstein AE, Plumb VJ, Bourge RC, Neves J, et al. Arrhythmias after orthotopic cardiac transplantation. Prevalence and determinants during initial hospitalization and late follow-up. Circulation. 1989;80(suppl):III140-6.

23. Ambrosi P, Ghez O, Riberi A, Metras D. Giant left atrial thrombus in a transplanted heart, Eur J Cardiothorac Surg. 2006;30:192.

24. Bernardi L. Influence of type of surgery on the occurrence of parasympathetic reinnervation after cardiac transplantation. Circulation. 1998;97:1368-74. 


\section{E-References}

E1. Wang S, Wildhirt SM, Johnston L, Koshal A, Mullen J, Ross D, et al. The Alberta adult heart transplant experience: survival based on age, gender, etiology, ischemic times, bridge to transplant, and bicaval technique. Transplant Proc. 2003;35:2471-4.

E2. Parry G, Holt ND, Dark JH, McComb JM. Declining need for pacemaker implantation after cardiac transplantation. Pacing Clin Electrophysiol. 1998;21(suppl):2350-2.

E3. Aleksic I, Freimark D, Blanche C, Czer LS, Takkenberg JJ, Dalichau $\mathrm{H}$, et al. Resting hemodynamics after total versus standard orthotopic heart transplantation in patients with high preoperative pulmonary vascular resistance. Eur J Cardiothorac Surg. 1997;11:1037-44.

E4. Freimark D, Czer LSC, Aleksic I, Barthold C, Admon D, Trento A, et al. Improved left atrial transport and function with orthotopic heart transplantation by bicaval and pulmonary venous anastomoses. $\mathrm{Am}$ Heart J. 1995;130:121-6.

E5. Freimark D, Silverman JM, Aleksic I, Crues JV, Blanche C, Trento A, et al. Atrial emptying with orthotopic heart transplantation using bicaval and pulmonary venous anastomoses: a magnetic resonance imaging study. J Am Coll Cardiol. 1995;25:932-6.

E6. Blanche C, Valenza M, Czer LS, Barath P, Admon D, Harasty D, et al. Orthotopic heart transplantation with bicaval and pulmonary venous anastomoses. Ann Thorac Surg. 1994;58:1505-9.

E7. Blanche C, Nessim S, Quartel A, Takkenberg JJ, Aleksic I, Cohen $\mathrm{M}$, et al. Heart transplantation with bicaval and pulmonary venous anastomoses. A hemodynamic analysis of the first 117 patients. J Cardiovasc Surg. 1997;38:561-6.

E8. Traversi E, Pozzoli M, Grande A, Forni G, Assandri J, Viganò M, et al. The bicaval anastomosis technique for orthotopic heart transplantation yields better atrial function than the standard technique: an echocardiographic automatic boundary detection study. J Heart Lung Transplant. 1998; 17:1065-74.

E9. Grande AM, Rinaldi M, D'Armini AM, Campana C, Traversi E, Pederzolli C, et al. Orthotopic heart transplantation: standard versus bicaval technique. Am J Cardiol. 2000;85:1329-33.

E10. Grant SCD, Khan MA, Faragher EB, Yonan N, Brooks NH. Atrial arrhythmias and pacing after orthotopic heart transplantation: bicaval versus standard atrial anastomosis. Br Heart J. 1995;74:149-53.

E11. El Gamel A, Yonan NA, Grant S, Deiraniya AK, Rahman AN, Sarsam MAI, et al. Orthotopic cardiac transplantation: a comparison of standard and bicaval Wythenshawe techniques. J Thorac Cardiovasc Surg. 1995;109:721-9.

E12. El Gamel A, Deiraniya AK, Rahman AN, Campbell CS, Yonan NA. Orthotopic heart transplantation hemodynamics: does atrial preservation improve cardiac output after transplantation? J Heart Lung Transplant. 1996;15:564-71.

E13. El Gamel A, Yonan NA, Keevil B, Warbuton R, Kakadellis J, Woodcook A, et al. Significance of raised natriuretic peptides after bicaval and standard cardiac transplantation. Ann Thorac Surg. 1997; 63:1095-100

E14. Rothman SA, Jeevanandam V, Combs WG, Furukawa S, Hsia HH, Eisen HJ, et al. Eliminating bradyarrhythmias after orthotopic heart transplantation. Circulation. 1996;94(suppl):278-82.

E15. Jeevanandam V, Russel H, Mather P, Furukawa S, Anderson A, Grzywacz F, et al. A one-year comparison of prophylactic donor tricuspid annuloplasty in heart transplantation. Ann Thorac Surg. 2004;78:759-66.

E16. Sievers HH, Leyh R, Jahnke A, Petry A, Kraatz EG, Herrman G, et al. Bicaval versus atrial anastomoses in cardiac transplantation. Right atrial dimension and tricuspid valve function at rest and during exercise up to thirty-six months after transplantation. $J$ Thorac Cardiovasc Surg. 1994;108:780-4.

E17. Leyh RG, Jahnke AW, Kraatz EG, Sievers HH. Cardiovascular dynamics and dimensions after bicaval and standard cardiac transplantation. Ann Thorac Surg. 1995;59:1495-500.

E18. Jahnke AW, Ley R, Bernhard A, Sievers HH. Atrial natriuretic peptide release at rest and with exercise after cardiac transplantation with bicaval anastomoses. J Thorac Cardiovasc Surg. 1995;110: $1600-5$.

E19. Beniaminowitz A, Savoia MT, Oz M, Galantowicz M, Di Tullio MR, Homma S, et al. Improved atrial function in bicaval versus standard orthotopic techniques in cardiac transplantation. Am J Cardiol 1997;80:1631-5.

E20. Laske A, Carrel T, Niederhäuser U, Pasic M, von Segesser LK, Jenni $\mathrm{R}$, et al. Modified operation technique for orthotopic heart transplantation. Eur J Cardiothorac Surg. 1995;9:120-6.

E21. Aziz T, Burgess MI, Rahman AN, Campbell CS, Deiraniya AK, Yonan NA. Risk factors for tricuspid valve regurgitation after orthotopic heart transplantation. Ann Thorac Surg. 1999;68:1247-51.

E22. Aziz T, Burgess M, Khafagy R, Wynn Hann A, Campbell C, Rahman A, et al. Bicaval and standard techniques in orthotopic heart transplantation: medium-term experience in cardiac performance and survival. J Thorac Cardiovasc Surg. 1999;118:115-22.

E23. Deleuze PH, Benvenuti C, Mazzucotelli JP, Perdrix C, Le Besnerais $\mathrm{P}$, Mourtada A, et al. Orthotopic cardiac transplantation with direct caval anastomosis: is it the optimal procedure? J Thorac Cardiovasc Surg. 1995;109:731-7.

E24. Milano CA, Shah ASJ, Van Trigt P, Jaggers J, Duane Davis R, Glower DD, et al. Evaluation of early postoperative results after bicaval versus standard cardiac transplantation and review of the literature. Am Heart J. 2000;140:717-21

E25. Koch A, Remppis A, Dengler TJ, Schnabel PA, Hagl S, Sack FU. Influence of different implantation techniques on AV valve competence after orthotopic heart transplantation. Eur J Cardiothorac Surg. 2005;28:717-23.

E26. Park K-Y, Park C-H, Chun Y-B, Shin M-S, Lee K-C. Bicaval anastomosis reduces tricuspid regurgitation after heart transplantation. Asian Cardiovasc Thorac Ann. 2005;13:241-54.

E27. Riberi A, Ambrosi P, Habib G, Kreitmann B, Yao JG, Gaudart J, et al. Systemic embolism: a serious complication after cardiac transplantation avoidable by bicaval technique. Eur J Cardiothorac Surg. 2001;19:307-11.

E28. Bouchart F, Derumeaux G, Mouton-Schleifer D, Beesou JP, Redonnet M, Soyer R. Conventional and total orthotopic cardiac transplantation: a comparative clinical and echocardiographical study. Eur J Cardiothorac Surg. 1997;12:555-9.

E29. Weisbrod CJ, Arnolda LF, McKitrick DJ, O’Driscoll G, Potter K, Green DJ. Vasomotor responses to decreased venous return: effects of cardiac deafferentation in humans. J Physiol. 2004;560(suppl): 919-27.

E30. Solomon NAG, McGiven JR, Alison PM, Ruygrok PN, Haydock DA, Coverdale HA, et al. Changing donor and recipient demographics in a heart transplantation program: influence on early outcome. Ann Thorac Surg. 2004;77:2096-102.

E31. Meyer SR, Modry DL, Bainey K, Koshal A, Mullen JC, Rebeyka IM, et al. Declining need for permanent pacemaker insertion with the bicaval technique of orthotopic heart transplantation. Can J Cardiol. 2005;21:159-63.

E32. Cui G, Tung T, Kobashiwaga J, Laks H, Sen L. Increased incidence of atrial flutter associated with the rejection of heart transplantation. Am J Cardiol. 2001;88:280-4.

E33. Brandt M, Harringer W, Hirt SW, Walluscheck KP, Cremer J, Sievers $\mathrm{HH}$, et al. Influence of bicaval anastomoses on late occurrence of atrial arrhythmia after heart transplantation. Ann Thorac Surg. 1997;64:70-2.

E34. Wang SS, Chu SH, Hsu RB, Chen YS, Chou NK, Ko WJ. Is bicaval anastomosis superior to standard atrial procedure of heart transplantation? Transplant Proc. 2000;32:2396-7.

E35. Forni A, Faggian G, Chiominto B, Perini G, Bertolini P, Zanini M, et al. Avoidance of atrioventricular valve incompetence following orthotopic heart transplantation using direct bicaval anastomosis. Transplant Proc. 1995;27:3478-82.

E36. Forni A, Faggian G, Luciani GB, Chiominto B, Perini G, Zanini M, et al. Reduced incidence of cardiac arrhythmias after orthotopic heart transplantation with direct bicaval anastomosis. Transplant Proc. 1996;28:289-92

E37. Trento A, Takkenberg JJ, Czer LS, Blanche C, Nessim S, Cohen M, et al. Clinical experience with one hundred consecutive patients undergoing orthotopic heart transplantation with bicaval and pulmonary venous anastomoses. J Thorac Cardiovasc Surg. 1996;112:1502-3.

E38. Luciani GB, Faggian G, Montalbano G, Forni A, Chiominto B, Mazzucco A. Orthotopic heart transplantation with bicaval 
anastomosis using older donors. Transplant Proc. 1997;29: 3389-91.

E39. Pahl E, Sunararaghavan S, Strasburger JF, Mitchell BM, Rodgers S, Crowley D, et al. Impaired exercise parameters in pediatric heart transplant recipients: comparison of biatrial and bicaval techniques. Pediatr Transplant. 2000;4:268-72.
E40. Sarsam MA, Campbell CS, Yonan NA, Deiraniya AK, Rahman AN. An alternative surgical technique in orthotopic cardiac transplantation. J Card Surg. 1993;8:344-9.

E41. McDowell G, Cave M, Bainbridge A, Danton M, Shaw C, Buchanan $\mathrm{KD}$, et al. Is the secretion of atrial natriuretic peptide in man under neural control? Eur Heart J. 2000;21:498-503. 


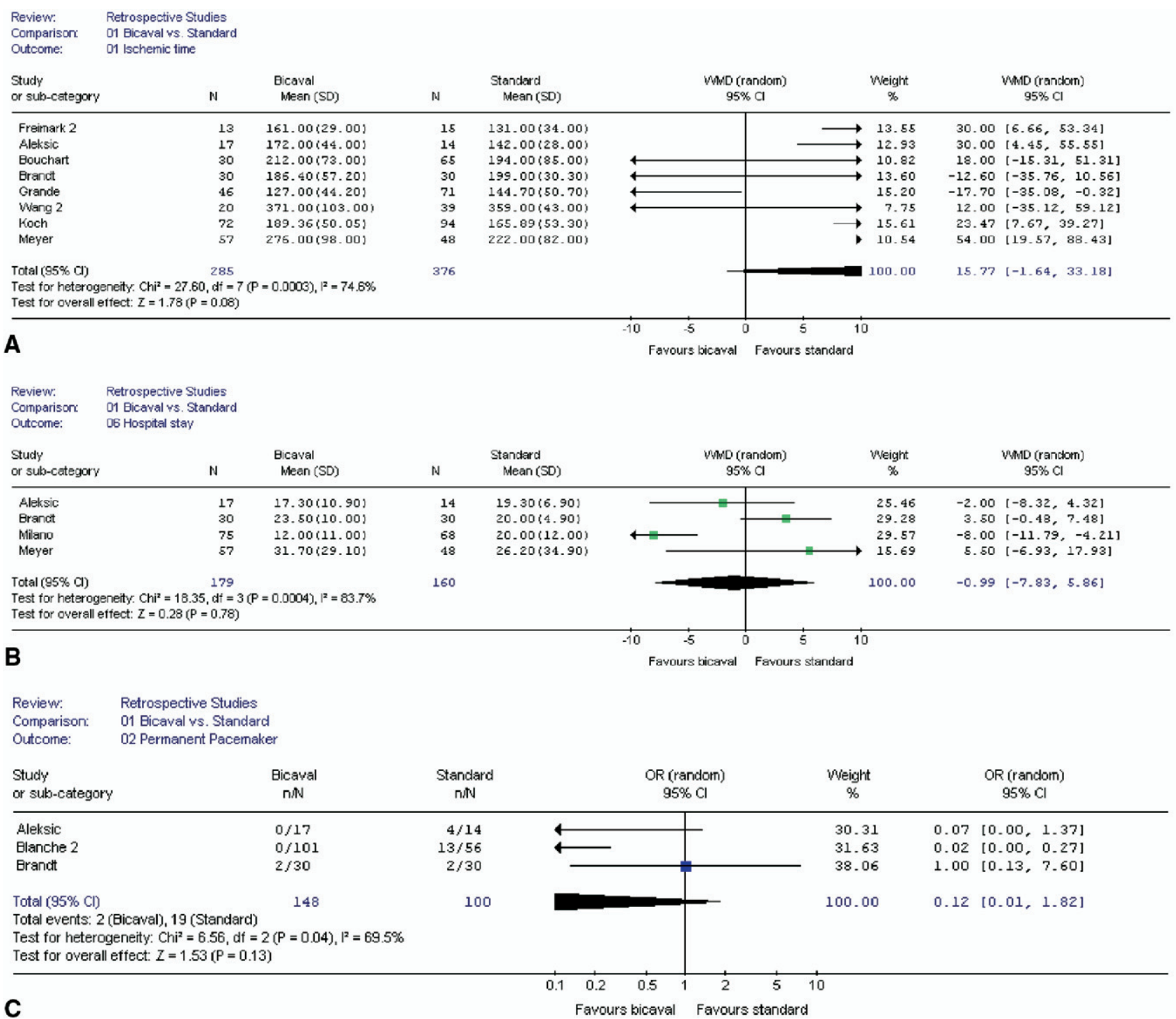

Figure E1. Meta-analyses of retrospective studies. A, Ischemic time. B, Hospital stay. C, Permanent pacemaker. D, One-year survival. E, Three-year survival. F, Sinus rhythm. SD, Standard deviation; WMD, weighted mean difference; $\mathrm{Cl}$, confidence interval; $\boldsymbol{O R}$, odds ratio. 


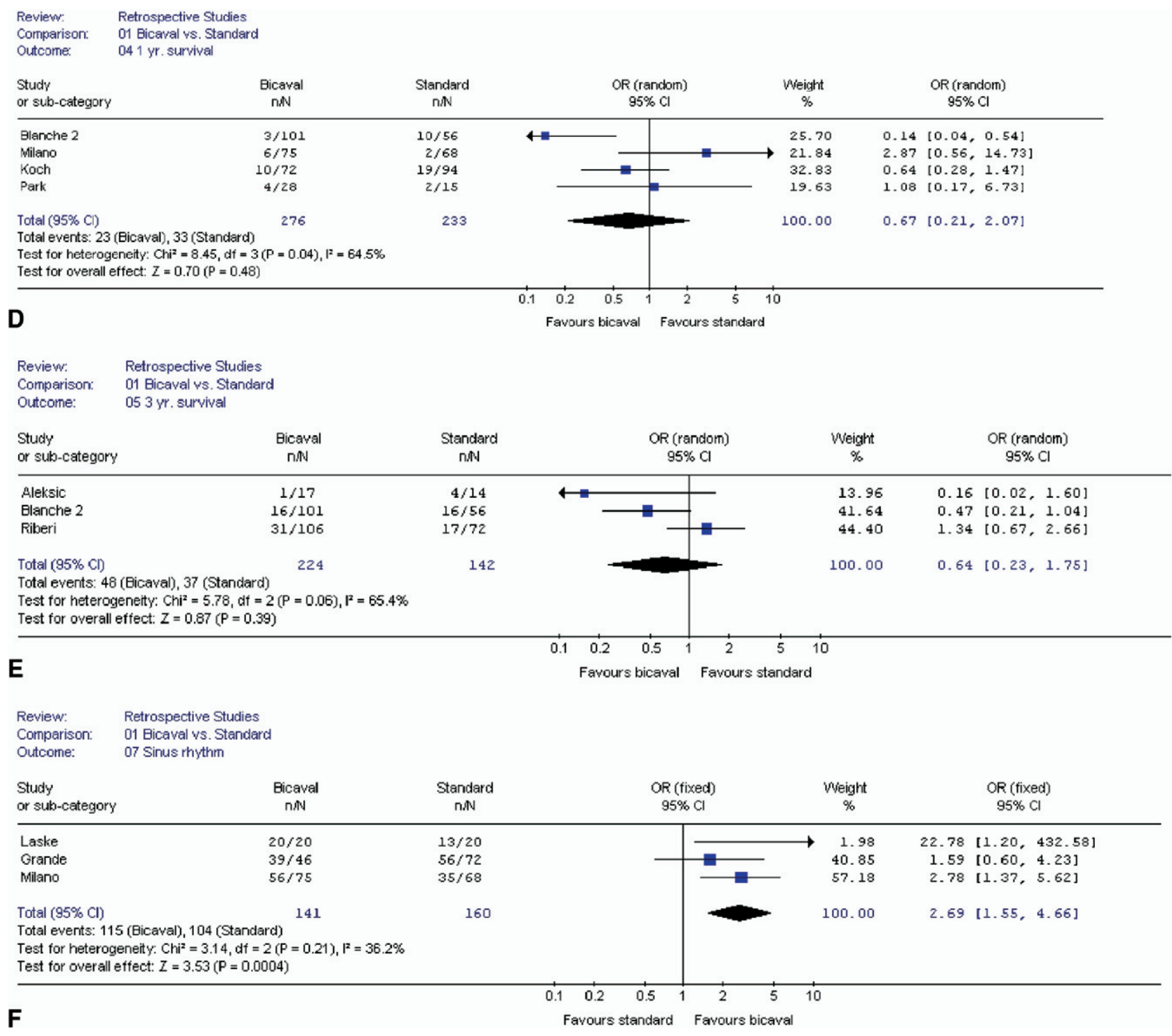

Figure E1. Continued 
TABLE E1. Results of the comparison of the outcomes between heart transplantation with the bicaval technique and the standard technique

\begin{tabular}{|c|c|c|c|c|}
\hline \multirow[b]{2}{*}{ Outcome parameter } & \multirow[b]{2}{*}{ Design } & \multicolumn{2}{|c|}{ Technique } & \multirow[b]{2}{*}{$P$ value } \\
\hline & & Bicaval & Standard & \\
\hline \multicolumn{5}{|l|}{ Temporary pacemaker } \\
\hline Grande and coworkers, $2000^{\mathrm{Eg}}$ & $\mathrm{R}$ & $28 \%$ & $44 \%$ & NS \\
\hline Laske and coworkers, 1996 E20 & $\mathrm{R}$ & $30 \%$ & $65 \%$ & $<.05$ \\
\hline Wang and coworkers, $2000^{\mathrm{E} 34}$ & $\mathrm{R}$ & $20 \%$ & $15 \%$ & NS \\
\hline El Gamel and coworkers, $1995^{\mathrm{E} 11}$ & $\mathrm{P}$ & $26 \%$ & $49 \%$ & $<.05$ \\
\hline Grant and coworkers, $1995^{\mathrm{E} 10}$ & $\mathrm{P}$ & $32.3 \%$ & $45.7 \%$ & NS \\
\hline Sarsam, $1993^{\mathrm{E} 40}$ & $P$ & $10 \%$ & $10 \%$ & NS \\
\hline \multicolumn{5}{|c|}{$\begin{array}{l}\text { Pulmonary vascular resistance } 12 \text { mo after } \\
\text { transplantation (Wood units) }\end{array}$} \\
\hline Grande and coworkers, $2000^{\mathrm{E9}}$ & $\mathrm{R}$ & $1.3 \pm 0.6$ & $1.4 \pm 0.6$ & NS \\
\hline Aleksic and coworkers, $1997^{\mathrm{E} 3}$ & $\mathrm{R}$ & $2.7 \pm 1.7$ & $1.7 \pm 0.7$ & NS \\
\hline \multicolumn{5}{|c|}{$\begin{array}{l}\text { Right atrial pressure } 12 \mathrm{mo} \text { after transplantation } \\
\qquad(\mathrm{mm} \mathrm{Hg})\end{array}$} \\
\hline Aleksic and coworkers, $1997^{E 3}$ & $\mathrm{R}$ & $5 \pm 2$ & $7 \pm 3$ & .07 \\
\hline Blanche and coworkers, $1997^{\mathrm{E}}$ & $\mathrm{R}$ & 4 & 6 & .006 \\
\hline Aziz and coworkers, $1999^{\mathrm{E} 22}$ & $\mathrm{P}$ & 5 & 11 & $\mathrm{NI}$ \\
\hline \multicolumn{5}{|c|}{ Cardiac index at first day $\left(\mathrm{L} \cdot \mathrm{min}^{-1} \cdot \mathrm{m}^{-2}\right)$} \\
\hline Milano and coworkers, $2000^{\mathrm{E} 24}$ & $\mathrm{R}$ & $3.1 \pm 0.7$ & $2.7 \pm 0.5$ & $<.05$ \\
\hline Deleuze and coworkers, $1995^{\mathrm{E} 23}$ & $\mathrm{R}$ & $4.1 \pm 0.9$ & $3.8 \pm 0.7$ & .04 \\
\hline Aziz and coworkers, $1999 \mathrm{a}^{\mathrm{E} 21}$ & $P$ & & & \\
\hline First period & & $3.7 \pm 1.1$ & $2.6 \pm 0.2$ & .02 \\
\hline Second period & & $3.9 \pm 0.5$ & $2.5 \pm 0.6$ & .03 \\
\hline \multicolumn{5}{|c|}{ Cardiac index at least $15 \mathrm{mo}\left(\mathrm{L} \cdot \mathrm{min}^{-1} \cdot \mathrm{m}^{-2}\right)$} \\
\hline Freimark and coworkers, $1995^{E 4}$ & & $2.8 \pm 0.7$ & $2.7 \pm 0.6$ & NS \\
\hline Leyh and coworkers, $1995^{\mathrm{E} 17}$ & & $3.2 \pm 0.5$ & $2.9 \pm 0.6$ & NS \\
\hline \multicolumn{5}{|c|}{ Sinus rhythm at end of cardiopulmonary bypass } \\
\hline Laske and coworkers, $1996^{\mathrm{E} 20}$ & $\mathrm{R}$ & $100 \%$ & $65 \%$ & $<.005$ \\
\hline Deleuze and coworkers, $1995^{\mathrm{E} 23}$ & $\mathrm{P}$ & $88 \%$ & $50 \%$ & $<.001$ \\
\hline \multicolumn{5}{|l|}{ Sinus rhythm at $1 \mathrm{wk}$} \\
\hline Milano and coworkers, $2000^{\mathrm{E} 24}$ & $\mathrm{R}$ & $74 \%$ & $50.7 \%$ & $<.05$ \\
\hline Rothman and coworkers, $1996^{\mathrm{E} 16}$ & $\mathrm{P}$ & $95 \%$ & $58 \%$ & $<.05$ \\
\hline \multicolumn{5}{|l|}{ Sinus rhythm at $1 \mathrm{mo}$} \\
\hline Grande and coworkers, $2000^{\mathrm{E9}}$ & $\mathrm{R}$ & $85 \%$ & $78 \%$ & NS \\
\hline \multicolumn{5}{|l|}{ Cardiac output (L/min) postoperatively } \\
\hline Koch and coworkers, $2005^{\mathrm{E} 25}$ & $\mathrm{R}$ & 5.5 & 5.0 & NS \\
\hline \multicolumn{5}{|l|}{$\begin{array}{l}\text { Cardiac output (L/min) at } 12 \mathrm{mo} \text { after } \\
\text { transplantation }\end{array}$} \\
\hline Grande and coworkers, 2000 & $\mathrm{R}$ & $4.7 \pm 1.1$ & $5.2 \pm 1.4$ & NS \\
\hline Blanche and coworkers, $1997^{\mathrm{E}}$ & $\mathrm{R}$ & 5.6 & 5.3 & NS \\
\hline Koch and coworkers, $2005^{\mathrm{E} 25}$ & $\mathrm{R}$ & 5.8 & 5.3 & NS \\
\hline \multicolumn{5}{|c|}{$\begin{array}{l}\text { Pulmonary artery pressure }(\mathrm{mm} \mathrm{Hg} \text { ) at } 12 \mathrm{mo} \\
\text { after transplantation }\end{array}$} \\
\hline Blanche and coworkers, $1997^{\mathrm{E7}}$ & $\mathrm{R}$ & $18.7(95 \% \mathrm{Cl}, 17.5-20.0)$ & $21.0(95 \% \mathrm{Cl}, 19.4-21.8)$ & .03 \\
\hline Koch and coworkers, $2005^{\mathrm{E} 25}$ & $\mathrm{R}$ & 18.5 & 18.5 & NS \\
\hline Aziz and coworkers, $1999 \mathrm{a}^{\mathrm{E} 21}$ & $P$ & & & \\
\hline First period & & $17.6 \pm 4.3$ & $22.8 \pm 5.1$ & .01 \\
\hline Second period & & $17.4 \pm 5.8$ & $21.9 \pm 5.8$ & .008 \\
\hline \multicolumn{5}{|c|}{$\begin{array}{l}\text { Systolic pressure }(\mathrm{mm} \mathrm{Hg}) \text { at least } 15 \mathrm{mo} \text { after } \\
\text { transplantation }\end{array}$} \\
\hline Freimark and coworkers, $1995^{E 5}$ & $\mathrm{R}$ & $133 \pm 20$ & $125 \pm 11$ & NS \\
\hline Weisbrod and coworkers, $2004^{\mathrm{E} 29}$ & $\mathrm{P}$ & $138 \pm 4$ & $122 \pm 7$ & NS \\
\hline
\end{tabular}


TABLE E1. Continued

\begin{tabular}{|c|c|c|c|c|}
\hline \multirow[b]{2}{*}{ Outcome parameter } & \multirow[b]{2}{*}{ Design } & \multicolumn{2}{|c|}{ Technique } & \multirow[b]{2}{*}{$P$ value } \\
\hline & & Bicaval & Standard & \\
\hline \multicolumn{5}{|l|}{ Mitral valve regurgitation } \\
\hline $\begin{array}{l}\text { Blanche and coworkers, } 1997^{\mathrm{E7}} ; 6-19 \mathrm{mo} \text { after } \\
\text { regurgitation }\end{array}$ & $\mathrm{R}$ & & & \\
\hline None & & $72 \%$ & $50 \%$ & .35 \\
\hline Mild & & $17 \%$ & $39 \%$ & \\
\hline Moderate & & $4 \%$ & $7 \%$ & \\
\hline Severe & & $0 \%$ & $4 \%$ & \\
\hline $\begin{array}{l}\text { Koch and coworkers, } 2005^{\mathrm{E} 25} \text {; at } 5 \text { y after } \\
\text { transplantation }\end{array}$ & $\mathrm{R}$ & & & \\
\hline None & & $100 \%$ & $98 \%$ & $<.05$ \\
\hline Mild & & $0 \%$ & $0 \%$ & NS \\
\hline Moderate & & $0 \%$ & $2 \%$ & NS \\
\hline Severe & & $0 \%$ & $0 \%$ & NS \\
\hline $\begin{array}{l}\text { El Gamel and coworkers, } 1995^{\mathrm{E11}} \text {; } 3 \text { mo after } \\
\text { transplantation }\end{array}$ & $P$ & & & \\
\hline None & & $85 \%$ & $60 \%$ & $<.05$ \\
\hline Mild & & $15 \%$ & $34 \%$ & \\
\hline Moderate & & $0 \%$ & $0 \%$ & \\
\hline Severe & & $0 \%$ & $6 \%$ & \\
\hline \multicolumn{5}{|l|}{ Moderate or severe tricuspid valve regurgitation } \\
\hline Milano and coworkers, $2000^{\mathrm{E} 24}$ & $\mathrm{R}$ & & & \\
\hline Month after transplantation & & $22 \%$ & $45 \%$ & $<.05$ \\
\hline Laske and coworkers, $19966^{\mathrm{E} 20}$ & $\mathrm{R}$ & & & \\
\hline 1-3 mo after transplantation & & $0 \%$ & $10 \%$ & NS \\
\hline Blanche and coworkers, $1997^{\mathrm{E7}}$ & $\mathrm{R}$ & & & \\
\hline 6-19 mo after transplantation & & $9 \%$ & $43 \%$ & $<.001$ \\
\hline Park and coworkers, $2005^{\mathrm{E} 26}$ & $\mathrm{R}$ & & & \\
\hline 1 y after transplantation & & $32 \%$ & $69 \%$ & .029 \\
\hline Koch and coworkers, $2005^{\mathrm{E} 25}$ & $\mathrm{R}$ & & & \\
\hline 5 y after transplantation & & $14 \%$ & $43 \%$ & $<.05$ \\
\hline El Gamel and coworkers, $1995^{E 11}$ & $P$ & & & \\
\hline 3 mo after transplantation & & $10 \%$ & $12 \%$ & NS \\
\hline Aziz and coworkers, $1999 a^{\mathrm{E} 21}$ & $\mathrm{P}$ & & & \\
\hline 2 y after transplantation & & $16 \%$ & $32 \%$ & .031 \\
\hline \multicolumn{5}{|l|}{$\begin{array}{l}\text { Left atrial thrombosis at least } 6 \text { mo after } \\
\text { transplantation }\end{array}$} \\
\hline Riberi and coworkers, $2001^{\mathrm{E} 27}$ & $\mathrm{R}$ & $0 \%$ & $12.5 \%$ & .04 \\
\hline Bouchart and coworkers, $1997^{\mathrm{E} 28}$ & $\mathrm{R}$ & $0 \%$ & $26.1 \%$ & .01 \\
\hline \multicolumn{5}{|l|}{$\begin{array}{l}\text { Peripheral atrial embolism at least } 6 \text { mo after } \\
\text { transplantation }\end{array}$} \\
\hline Bouchart and coworkers, $1997^{\mathrm{E} 28}$ & $\mathrm{R}$ & $0 \%$ & $13.8 \%$ & NS \\
\hline \multicolumn{5}{|l|}{ Intensive care unit stay (d) } \\
\hline Freimark and coworkers, $1995^{E 5}$ & $\mathrm{R}$ & $6.0 \pm 3.6$ & $5.8 \pm 2.3$ & NS \\
\hline Aziz and coworkers, $1999 \mathrm{a}^{\mathrm{E} 21}$ & $P$ & & & \\
\hline First period & & $5.6 \pm 2.0$ & $3.5 \pm 2.5$ & .007 \\
\hline Second period & & $4.5 \pm 2.5$ & $3.2 \pm 1.9$ & .02 \\
\hline
\end{tabular}

$R$, Retrospective; $N S$, nonsignificant; $P$, prospective; $N I$, no information; $C l$, confidence interval. 
TABLE E2. Sensitivity analysis: Comparison of random- and fixed-effect models

\begin{tabular}{lcc}
\hline Parameter & Fixed-effect model WMD or OR (95\% CI) & Random-effect model WMD or OR (95\% Cl) \\
\hline Prospective studies & & $3.56(-5.52$ to 12.83$)$ \\
Ischemic time & $3.66(-5.52$ to 12.85$)$ & $-3.95(-6.50$ to -1.40$)$ \\
Early atrial pressure & $-4.97(-5.77$ to -4.17$)$ & $0.46(0.18$ to 1.13$)$ \\
Perioperative mortality & $0.41(0.17$ to 0.98$)$ & $0.23(0.15$ to 0.36$)$ \\
Tricuspid valve regurgitation & $0.23(0.15$ to 0.36$)$ & $7.03(2.59$ to 19.12$)$ \\
Sinus rhythm & $7.01(2.57$ to 19.13$)$ & $15.77(-1.64$ to 33.18$)$ \\
Retrospective studies & & $-0.99(-7.83$ to 5.06$)$ \\
Ischemic time & $12.22(3.99$ to 20.46$)$ & $0.12(0.01$ to 1.02$)$ \\
Hospital stay & $-2.14(-4.61$ to 0.32$)$ & $0.60(0.14$ to 2.53$)$ \\
Permanent pacemaker & $0.10(0.03$ to 0.33$)$ & $0.64(0.23$ to 1.75$)$ \\
1-y Survival & $0.57(0.31$ to 1.04$)$ & $2.59(1.15$ to 5.84$)$ \\
3-y Survival & $0.78(0.48$ to 1.28$)$ & $2.69(1.55$ to 4.66$)$ \\
Sinus rhythm &
\end{tabular}

$W M D$, Weighted mean difference; $O R$, odds ratio; $C l$, confidence interval.

TABLE E3. Sensitivity analysis: Exclusion of influential studies

\begin{tabular}{|c|c|c|c|}
\hline Parameter & Original model WMD or OR $(95 \% \mathrm{Cl})^{*}$ & Exclusion of study & Model after exclusion WMD or OR $(95 \% \mathrm{CI})^{*}$ \\
\hline \multicolumn{4}{|l|}{ Prospective studies } \\
\hline Early atrial pressure & $-3.95(-6.50$ to -1.40$)$ & Deleuze ${ }^{\mathrm{E} 23}$ & $-5.42(-6.69$ to -4.15$)$ \\
\hline Perioperative mortality & $0.41(0.17$ to 0.98$)$ & Rothman ${ }^{\mathrm{E} 14}$ & $0.37(0.15$ to 0.95$)$ \\
\hline Tricuspid valve regurgitation & $0.23(0.15$ to 0.36$)$ & El Gamel $2^{\mathrm{E} 12}$ & $0.20(0.13$ to 0.32$)$ \\
\hline \multicolumn{4}{|l|}{ Retrospective studies } \\
\hline Hospital stay & $-0.99(-7.83$ to 5.06$)$ & Milano ${ }^{\text {E24 }}$ & $2.01(-1.82$ to 5.84$)$ \\
\hline Permanent pacemaker & $0.12(0.01$ to 1.02$)$ & Brandt ${ }^{\mathrm{E} 33}$ & $0.03(0$ to 0.25$)$ \\
\hline 1-y Survival & 0.60 (0.14 to 2.53$)$ & Milano E24 & 0.33 (0.08 to 1.43$)$ \\
\hline 3-y Survival & $0.64(0.23$ to 1.75$)$ & Riberi ${ }^{\text {E27 }}$ & 0.42 (0.20 to 0.89$)$ \\
\hline
\end{tabular}

$W M D$, Weighted mean difference; $O R$, odds ratio; $C l$, confidence interval. *All random effect model if not specified otherwise. 